Article

\title{
Blackcurrant Alters Physiological Responses and Femoral Artery Diameter during Sustained Isometric Contraction
}

\author{
Matthew David Cook ${ }^{1,2}$, Stephen David Myers ${ }^{1}$, Mandy Lucinda Gault ${ }^{1}$ and \\ Mark Elisabeth Theodorus Willems ${ }^{1, *}$ \\ 1 Department of Sport \& Exercise Sciences, University of Chichester, College Lane, Chichester PO19 6PE, UK; \\ matthew.cook@worc.ac.uk (M.D.C.); s.myers@chi.ac.uk (S.D.M.); m.gault@chi.ac.uk (M.L.G.) \\ 2 Institute of Sport and Exercise Science, University of Worcester, Henwick Grove, Worcester WR2 6AJ, UK \\ * Correspondence: m.willems@chi.ac.uk; Tel.: +44-012-4381-6468
}

Received: 26 April 2017; Accepted: 26 May 2017; Published: 29 May 2017

\begin{abstract}
Blackcurrant is rich in anthocyanins that may affect exercise-induced physiological responses. We examined tissue oxygen saturation, muscle activity, cardiovascular responses and femoral artery diameter during a submaximal sustained isometric contraction. In a randomised, double-blind, crossover design, healthy men $\left(n=13\right.$, age: $25 \pm 4$ years, BMI: $25 \pm 3 \mathrm{~kg} \cdot \mathrm{m}^{-2}$, mean \pm SD) ingested New Zealand blackcurrant (NZBC) extract $\left(600 \mathrm{mg} \cdot\right.$ day $^{-1}$ CurraNZ $^{\mathrm{TM}}$ ) or placebo (PL) for 7-days separated by 14-days washout. Participants produced isometric maximal voluntary contractions (iMVC) and a 120-s 30\%iMVC of the quadriceps with electromyography (EMG), near-infrared spectroscopy, hemodynamic and ultrasound recordings. There was no effect of NZBC extract on iMVC (NZBC: $654 \pm 73$, PL: $650 \pm 78$ N). During the 30\%iMVC with NZBC extract, total peripheral resistance, systolic, diastolic, and mean arterial pressure were lower with increased cardiac output and stroke volume. With NZBC extract, EMG root mean square of the vastus medialis and muscle oxygen saturation were lower with higher total haemoglobin. During the $30 \% \mathrm{iMVC}$, femoral artery diameter was increased with NZBC extract at $30(6.9 \%), 60(8.2 \%), 90(7.7 \%)$ and $120 \mathrm{~s}$ $(6.0 \%)$. Intake of NZBC extract for 7-days altered cardiovascular responses, muscle oxygen saturation, muscle activity and femoral artery diameter during a 120-s 30\%iMVC of the quadriceps. The present study provides insight into the potential mechanisms for enhanced exercise performance with intake of blackcurrant.
\end{abstract}

Keywords: cardiovascular function; anthocyanins; blood flow; isometric contraction; New Zealand blackcurrant; electromyography; ultrasound; exercise

\section{Introduction}

Blackcurrant contains a high and specific content of anthocyanins [1], considered to be the essential bioactive berry compounds. New Zealand blackcurrant (NZBC) altered cardiovascular function in rest by increased cardiac output [2,3], and improved cycling endurance [4] and repeated high-intensity running performance [5]. However, the mechanisms for the ergogenic effects of New Zealand blackcurrant are unknown. Matsumoto et al. [6] observed with blackcurrant intake an increase in forearm blood flow at rest following arterial occlusion, and a higher change in total haemoglobin in the trapezius muscle during a maximal voluntary contraction (MVC) after $30 \mathrm{~min}$ of typing, measured by infrared spectroscopy (NIRS). Such observations may be mediated by the blackcurrant anthocyanins (or metabolites) influencing vasodilation and relaxation [7], by increasing production of nitric oxide. Other in vivo studies also observed anthocyanins to vasodilate blood 
vessels by increasing flow-mediated dilation at rest $[8,9]$. However, the potential effects of NZBC on enlarging blood vessel diameter during exercise have not been examined.

It is important to note that Matsumoto et al. [6] reported the increase in peripheral blood flow of the forearm from a rate of increase in total haemoglobin after releasing an occlusion by a pressured cuff around the upper arm. However, NIRS only provides a proxy measure of blood flow as a change would assume muscle perfusion from an artery to be greater, i.e., as a result of vasodilation or increased flow rate.

Because muscle blood flow is of critical importance in oxygen delivery for muscle metabolism, an impediment of blood flow will precipitate fatigue. Blood flow into muscle is sensitive to the intensity and type of contraction [10-12]. Sustained isometric contractions present a challenge to muscle blood perfusion as the increased demand for flow is counteracted by the increased intramuscular pressure. For example, it has been observed that with muscle forces above $30 \%$ of MVC, blood flow becomes impaired as intramuscular pressure rises above that of systolic blood pressure in the elbow flexors, knee extensors and plantar flexors [11] and handgrip flexors [12]. McNeil et al. [10] also observed that there was no change in anterior tibial artery diameter during a 60 -s isometric contraction at $30 \%$ of MVC, but it was significantly compressed at $60 \%$ and $100 \%$ of MVC. Therefore, sustained isometric exercise presents a challenge to blood flow and nutritional interventions that can alter responses to benefit blood flow are potentially of interest to athletes undertaking exercise where prolonged isometric force production is required.

Motor unit behaviour during sustained isometric contractions indicates a decline in firing rate, with the recruitment of additional motor units as the contraction duration continues [13]. It has been suggested that the decrease in motor unit firing rate is mediated by chemoreceptive small diameter afferent nerves (groups III, IV) [13,14]. Afferent III and IV nerves respond to by-products of muscle contraction $[15,16]$. Therefore, during a submaximal isometric contraction, an increase in vasodilation of an artery by NZBC supplying an exercising muscle would be expected to increase muscle perfusion and lead to a reduction in by-products acting upon these afferent nerves. This would then be expected to lower recruitment of muscle fibres to compensate for fatigue within other fibres and in turn, result in a reduced root mean square (RMS) measured during electromyography. The effect of blackcurrant upon motor unit behaviour during isometric contraction is unknown.

The aim of the present study was to examine the effect of a New Zealand blackcurrant extract on blood vessel diameter, cardiovascular responses, muscle activity, and muscle oxygen saturation during a sustained submaximal isometric contraction.

\section{Materials and Methods}

\subsection{Participants}

Thirteen men (age: $25 \pm 4$ years (range 21-35 years), height: $182 \pm 6 \mathrm{~cm}$, body mass: $82 \pm 9 \mathrm{~kg}$, body fat: $13 \pm 3 \%$, BMI: $25 \pm 3 \mathrm{~kg} \cdot \mathrm{m}^{-2}$ (range $20.6-29.9 \mathrm{~kg} \cdot \mathrm{m}^{-2}$, six with BMI between 18.5 and 24.9, seven with BMI between 25 and 29.9) provided written informed consent to participate in the study. Participants were healthy, physically active, non-smokers, and without history of musculoskeletal injury. Participants were not involved in a structured training programme at the time of the study and were not taking dietary supplements and prescription and non-prescription drugs. The study was approved by the University of Chichester Research Ethics Committee (approval code: 1617_38) with protocols and procedures performed in accordance with the ethical principles outlined by the Declaration of Helsinki (World Medical Association, 2013).

\subsection{Experimental Design}

Participants visited the laboratory for 3 visits, at the same time of day ( 8:00 am). During the first visit, height (Harpenden Wall Mounted Stadiometer, UK), body mass (Kern ITB, Kern, Germany) and body fat were measured (Tanita BC418 Segmental Body Composition analyzer, Tanita, IL, USA). 
A testing bench was adjusted to fit participants so that hip and knee angle was $90^{\circ}$. The femoral artery was then identified by ultrasound (MicroMaxx Doppler ultrasound, Sonosite, Inc; Bothwell, WA, USA) for measurement of resting diameter (method adapted from Shoemaker et al. [17]). Electromyography electrodes were placed upon the skin to record signals from the vastus medialis, rectus femoris and biceps femoris muscles. This was followed by participants completing three maximal voluntary contractions of the knee extensors with EMG recording (Delsys Bagnoli-8 system, Delsys Inc., Boston, MA, USA). A line was placed upon the computer screen to represent $30 \%$ iMVC (i.e., isometric maximal voluntary contraction) (calculated from the highest force during the 3 iMVCs), which participants produced for $120 \mathrm{~s}$. During the sustained isometric contraction, whole body cardiovascular measurements were recorded using a beat-to-beat blood pressure monitoring system (Portapres ${ }^{\circledR}$ Model 2, Finapres Medical Systems BV, Amsterdam, The Netherlands), muscle oxygen saturation of the rectus femoris muscle measured using NIRS (Moxy Monitor, Hutchinson, MN, USA), EMG recorded and diameter of the femoral artery measured by ultrasound. The first visit allowed participants to become familiarised with all testing procedures before the experimental conditions in visits 2 and 3 .

For 7-days prior to visits 2 and 3, participants consumed $2 \times 300 \mathrm{mg}$ capsules (total 210 mg of anthocyanins) of NZBC extract (CurraNZ ${ }^{\mathrm{TM}}$, Health Currancy Ltd, Surrey, UK) or identical looking placebos $(2 \times 300 \mathrm{mg}$ microcrystalline cellulose M102) every morning with breakfast. Each capsule of $300 \mathrm{mg}$ contains $105 \mathrm{mg}$ of anthocyanins, i.e., 35\%-50\% delphinidin-3-rutinoside, $5 \%-20 \%$ delphinidin-3-glucoside, 30\%-45\% cyanidin-3-rutinoside, and 3\%-10\% cyanidin-3-glucoside with remaining content mainly natural plant sugars. The dose used was established from a previous study in which a dose-response relationship in cardiovascular responses was observed in trained cyclists [2]. Optimal dosing strategy for New Zealand blackcurrant extract is not known. However, previous studies on effects of fruit juices dosed also for multiple days before exercise testing (e.g., 4 days tart cherry juice [18], 6 days tart cherry juice [19], and 8 days montmorency cherry juice [20]). On the final day of supplementation in the present study, participants reported to the laboratory, two hours post-prandial of a standard breakfast (i.e., one slice of buttered bread or toast $\sim 840 \mathrm{~kJ}, \sim 30$ $\mathrm{g}$ carbohydrate, $\sim 6 \mathrm{~g}$ protein and $\sim 7 \mathrm{~g}$ fat) and the capsules required for that condition. The two experimental conditions (NZBC extract and placebo) were performed in a randomised double-blind, cross-over design with a 14-day washout period. Seven participants received NZBC extract as the first condition.

\subsection{Isometric Maximum Voluntary Contraction}

A metal cuff with soft strap was attached to the ankle of the participant proximal to the fibular notch and medial malleolus and attached via steel chain to an s-beam load cell (RS $250 \mathrm{~kg}$, Teda Hutleigh Cardiff, UK). Participants then completed three warm up isometric contractions ( $\sim 50 \%$ MVC held for $5 \mathrm{~s}$ ) prior to performing three isometric MVCs with standardised instructions [21]. Each iMVC lasted approximately $3-4 \mathrm{~s}$ with the highest mean force produced for $0.5 \mathrm{~s}$ during the three contractions taken as iMVC force. EMG measurements were recorded during each iMVC. Between MVCs, participants rested for $2 \mathrm{~min}$. A screen displaying force was placed in front of participants and recorded on computer at $1000 \mathrm{~Hz}$ using Chart 4 V4. 1.2 (AD Instruments, Oxford, UK). All testing was performed with the dominant leg.

\subsection{Ultrasound of Femoral Artery}

The femoral artery was insonated by ultrasound (MicroMaxx portable ultrasound, Sonosite, Bothell, WA, USA) with an 8-Mhz linear array transducer in B-mode and an angle of approach at $90^{\circ}$. Participants were scanned while sitting on the isometric chair with the hip angle at $90^{\circ}$, and with the probe in the transverse plane, approximately $7 \mathrm{~cm}$ below the inguinal ligament to avoid the femoral artery bifurcation. Arterial diameter measurements were made from the average of 3 frozen images during diastole [17] at rest and 30, 60, 90 and $120 \mathrm{~s}$ during the sustained isometric contraction. 


\subsection{Near Infrared Spectroscopy}

The NIRS was taped centrally on the rectus femoris and recorded at a sampling frequency of $2 \mathrm{~Hz}$ and at wavelengths of $630 \mathrm{~nm}$ and $850 \mathrm{~nm}$. Muscle oxygen saturation $\left(\mathrm{SmO}_{2} \%\right)$ and haemoglobin concentration $(\mathrm{THb})$ was measured at rest and 15, 30, 45, 60, 75, 90, 105 and $120 \mathrm{~s}$ in the sustained isometric contraction, with six measurements averaged and centred around each time point.

\subsection{Electromyography}

Electromyography signals (bandwidth $=20$ to $240 \mathrm{~Hz}$; common mode rejection ratio $=92 \mathrm{~dB}$; input impedance $\geq 1015 \Omega$ ) of the vastus medialis, rectus femoris and biceps femoris were taken during the iMVC and sustained isometric contraction. To ensure accurate electrode positioning in all trials, the recommendations for placement followed guidelines by SENIAM (http://www.seniam.org/). The skin was prepared by shaving, cleansing and abrading to minimize skin-to-electrode impedance. The electrode was placed transverse to the muscle fibre pennation angle and attached the skin with tape. A reference electrode was placed approximately $4 \mathrm{~cm}$ proximal to the patella apex of the leg measured.

EMG data were collected and processed using Delsys EMGworks ${ }^{\circledR}$ Acquisition and Analysis software (Delsys INC, Boston, MA, USA). Raw EMG signals were amplified at $1000 \mathrm{~Hz}$, and then filtered using a 2nd order Butterworth bandpass filter (low $10 \mathrm{~Hz}$, high $350 \mathrm{~Hz}$ ). The Root Mean Square (RMS) of the filtered signal $(\mathrm{mV})$ was calculated using a moving window (window length $0.05 \mathrm{~s}$, window overlap $0.025 \mathrm{~s}$ ). The RMS data are expressed as normalized values from the highest RMS value sustained for $0.5 \mathrm{~s}$ during the iMVC. During the 120-s contraction, the calculated RMS values were averaged around the centred time point (e.g., 14.5-15.5 s) for the 15, 30, 45, 60, 75, 90, 105 and $120 \mathrm{~s}$ during the sustained isometric contraction. From the filtered signal, the median frequency (MDF) was calculated with a moving window (window length: $1 \mathrm{~s}$, window overlap: $0.5 \mathrm{~s}$ ). The mean slope by linear regression analysis of the MDF was calculated for all values of the sustained isometric contraction.

\subsection{Cardiovascular Measurements}

Cardiovascular responses were recorded using a beat-to-beat blood pressure monitoring system during $10 \mathrm{~min}$ of rest in a sitting position using the arterial volume clamp method [22]. The Portapres ${ }^{\circledR}$ is a beat-to-beat finger blood pressure analyser that allows the non-invasive continuous measurement of haemodynamic parameters. The finger cuff was positioned around the same finger of the left hand. Cardiovascular recordings in rest were averaged over 10 consecutive beats, with the lowest systolic blood pressure and associated measures recorded. This approach avoids selection of signal content. During the sustained isometric contraction, the participants were instructed to keep the left hand stationary in their lap. Cardiovascular recordings during the sustained isometric contraction were averaged over 6 consecutive beats centred around each time point of the $120 \mathrm{~s}$ contraction (i.e., 15, 30, 45, 60, 90, 105 and 120 s). The following parameters were derived: stroke volume, cardiac output, systolic blood pressure, diastolic blood pressure, mean arterial blood pressure, ejection time, and total peripheral resistance (Beatscope 1.1a., Finapres Medical Systems BV, Amsterdam, The Netherlands).

\subsection{Physical Activity and Dietary Standardisation}

Participants were instructed to keep their weekly exercise schedule as consistent as possible. Before all visits to the laboratory, participants were instructed not to exercise and consume alcohol $24 \mathrm{~h}$ before, not to consume caffeine $4 \mathrm{~h}$ before, and not take other dietary supplements that add further nutritional value to the normal diet.

Participants recorded their dietary intake and exercise on a written diary $48 \mathrm{~h}$ prior to the first experimental condition (i.e., visit 2) and were instructed for the subsequent experimental visit (i.e., visit 3) to replicate intake using the diary as a guide, while recording on a new diary their dietary intake for that visit. Participants confirmed adherence to the study criteria at the start of every visit. Food diaries 
were analysed using Nutritics (Nutritics LTD, Dublin, Ireland) for carbohydrate, fat and protein intake and total energy intake $(\mathrm{kJ})$. There were no differences $(p>0.05)$ in absolute values or relative values (i.e., per kilogram of body mass) for carbohydrate, fat, protein, or total energy intake for $48 \mathrm{~h}$ prior to each experimental visit (Table 1). Analysis of the food diaries identified that all participants reported $100 \%$ adherence to the dietary instructions $48 \mathrm{~h}$ prior to each visit.

Table 1. Absolute and relative to body mass dietary intake $48 \mathrm{~h}$ before each visit for placebo and NZBC extract condition.

\begin{tabular}{ccc}
\hline Dietary Variable & Placebo & NZBC Extract \\
\hline Carbohydrate $(\mathrm{g})$ & $499 \pm 81$ & $491 \pm 73$ \\
$(\mathrm{~g} \cdot \mathrm{kg}$ body mass & -1 \\
Fat $(\mathrm{g})$ & $6.8 \pm 1.4$ & $6.7 \pm 1.4$ \\
$\left(\mathrm{~g} \cdot \mathrm{kg} \mathrm{body} \mathrm{mass}^{-1}\right)$ & $230 \pm 61$ & $225 \pm 69$ \\
Protein $\left.(\mathrm{g})_{(\mathrm{g} \cdot \mathrm{kg} \text { body mass }}{ }^{-1}\right)$ & $3.7 \pm 1.1$ & $3.9 \pm 0.6$ \\
Total energy intake $(\mathrm{kJ})$ & $219 \pm 47$ & $231 \pm 46$ \\
$\left(\mathrm{~kJ} \cdot\right.$ body mass $\left.^{-1}\right)$ & $20,764 \pm 2835$ & $2.9 \pm 0.9$ \\
\hline
\end{tabular}

NZBC, New Zealand blackcurrant; values are means \pm SD for 13 participants.

\subsection{Statistical Analysis}

Statistical analyses were completed using SPSS 20.0 (SPSS, Chicago, IL, USA). Data normality assumptions were assessed using Kolmogorov-Smirnov test. Paired samples t-tests used were to compare maximal force during the iMVCs, mean of the sustained isometric force during the $30 \%$ iMVC, resting cardiovascular function, resting muscle oxygen saturation, femoral artery diameter and the 48-h dietary intake between the NZBC and placebo conditions. Differences between cardiovascular function and EMG during the sustained isometric contraction were analysed using a condition (control vs. NZBC) by time-point $(15,30,45,60,75,90,105$, and $120 \mathrm{~s})$ repeated measures analysis of variance (ANOVA) with LSD post hoc comparisons. Differences between the femoral artery diameter during the sustained contraction were analysed using a condition by time-point (30, 60, 90 and 120 s) repeated measures ANOVA with LSD post hoc comparisons. Mauchley's Test of Sphericity was conducted to test for homogeneity of data and where violations were present; Greenhouse-Geiser adjustments were made. To determine the effect size of responses, Cohen's $d$ were calculated [23]. Cohen [23] described an effect size of $<0.2$ as a trivial, $0.2-0.39$ as a small, $0.4-0.69$ as a moderate and $\geq 0.7$ as a large magnitude of change. From the $15 \%$ change in cardiac output following $600 \mathrm{mg} \cdot \mathrm{day}^{-1} \mathrm{of}$ NZBC extract in Cook et al. [2], an a-priori power analysis indicated a sample size of 13 would allow a detection of a $15 \%$ increase in cardiac output with a high statistical power $(1-\beta=0.95: 0.05=\alpha$ level). All data are reported as mean \pm SD and significance was accepted at $p<0.05$.

\section{Results}

\subsection{Isometric Maximal Voluntary Contraction and Sustained Isometric Force}

There was no effect of NZBC on maximal isometric voluntary contraction force (NZBC: $654 \pm 73$, PL: $650 \pm 78 \mathrm{~N}, p=0.732$ ) or average force during the sustained isometric contraction for $120 \mathrm{~s}$ (NZBC: $182 \pm 24$, PL: $182 \pm 23 \mathrm{~N}, p=0.934)$.

\subsection{Cardiovascular Function in Rest}

At rest, before the sustained isometric contraction, there were no differences in systolic blood pressure (NZBC: $126 \pm 11$, PL: $126 \pm 11 \mathrm{mmHg}, p=0.901)$, diastolic blood pressure (NZBC: $75 \pm 10$, PL: $72 \pm 9 \mathrm{mmHg}, p=0.319)$, mean arterial pressure (NZBC: $91 \pm 10$, PL: $89 \pm 10 \mathrm{mmHg}, p=0.553$ ), heart rate (NZBC: $75 \pm 8$, PL: $71 \pm 10$ beats $\cdot \mathrm{min}^{-1}, p=0.204$ ) and ejection time (NZBC: $0.27 \pm 0.02, \mathrm{PL}$ : 
$0.27 \pm 0.01 \mathrm{~s}, p=0.330$ ). Cardiac output (NZBC: $6.6 \pm 1.6, \mathrm{PL}: 5.5 \pm 1.4 \mathrm{~L} \cdot \mathrm{min}^{-1}, p=0.001, d=0.73$ ) and stroke volume (NZBC: $90 \pm 17$, PL: $80 \pm 18 \mathrm{~mL}, p=0.015, d=0.57$ ) were increased by $16 \%$ and $11 \%$, respectively. There was a $25 \%$ lower total peripheral resistance (NZBC: $14.3 \pm 4.1$, PL $17.3 \pm 4.2$ $\left.\mathrm{mmHg} \cdot \mathrm{L}^{-1} \cdot \mathrm{min}^{-1}, p=0.003, d=0.72\right)$. The changes in resting cardiovascular function were observed in 12 participants.

\subsection{Cardiovascular Responses during the Sustained Isometric Contraction}

During the $120 \mathrm{~s}$ isometric contraction, systolic blood pressure was different between the conditions $\left(\mathrm{F}_{(1,96)}=41.41, p<0.001\right)$ with a time effect $\left(\mathrm{F}_{(7,96)}=3.28, p=0.004\right)$ and no interaction effect $\left(\mathrm{F}_{(7,96)}=0.58, p=0.778\right)$. With NZBC, systolic pressure was lower at $15(7 \%, p=0.036, d=0.48)$, $30(10 \%, p=0.020, d=0.68), 45(9 \%, p=0.023, d=0.60), 75(12 \%, p=0.003, d=0.92)$ and $90 \mathrm{~s}(11 \%$, $p=0.008, d=0.73$ ) (Figure 1a). At $105 \mathrm{~s}$, there was a trend for systolic pressure to be lower with NZBC $(p=0.083)$. Diastolic pressure was different between the conditions $\left(\mathrm{F}_{(1,96)}=35.27, p<0.001\right)$ with a time effect $\left(\mathrm{F}_{(7,96)}=3.65, p=0.002\right)$ and no interaction effect $\left(\mathrm{F}_{(7,96)}=0.21, p=0.982\right)$. With NZBC, diastolic pressure was lower at $15(7 \%, p=0.020, d=0.46), 30(7 \%, p=0.044, d=0.30), 45(8 \%, p=0.022$, $d=0.47), 60(8 \%, p=0.011, d=0.47)$ and $75 \mathrm{~s}(9 \%, p=0.008, d=0.56)$. There were trends for diastolic pressure to be lower with NZBC at $90(p=0.060)$ and $105 \mathrm{~s}(p=0.064)$ (Figure 1b). Mean arterial pressure was different between the conditions $\left(\mathrm{F}_{(1,96)}=39.55, p<0.001\right)$ with a time effect $\left(\mathrm{F}_{(7,96)}=5.37\right.$, $p<0.001)$ and no interaction effect $\left(\mathrm{F}_{(6,96)}=0.62, p=0.735\right)$. NZBC decreased mean arterial pressure at $15(7 \%, p=0.022, d=0.44), 30(9 \%, p=0.020, d=0.58), 45(9 \%, p=0.009, d=0.59), 60(8 \%, p=0.008$, $d=0.52), 90(10 \%, p=0.008, d=0.76)$ and $105 \mathrm{~s}(13 \%, p=0.018, d=0.89)$ (Figure 1c).

Heart rate was not different between the conditions $\left(\mathrm{F}_{(1,96)}=1.61, p=0.207\right)$, with no time $\left(\mathrm{F}_{(7,96)}\right.$ $=1.02, p=0.420)$ or interaction effect $\left(\mathrm{F}_{(7,96)}=0.45, p=0.868\right)$ (Figure 1d). Similarly, ejection time was not different between the conditions $\left(\mathrm{F}_{(1,96)}=0.16, p=0.688\right)$, with no time $\left(\mathrm{F}_{(7,96)}=0.61, p=0.744\right)$, or interaction effect $\left(\mathrm{F}_{(7,96)}=0.27, p=0.963\right)$ (Figure 1e).

Stroke volume was different between the conditions $\left(\mathrm{F}_{(1,96)}=9.81, p=0.002\right)$, with no time $\left(\mathrm{F}_{(7,96)}\right.$ $=0.47, p=0.865)$ or interaction effect $\left(\mathrm{F}_{(7,96)}=0.17, p=0.990\right)$. NZBC increased stroke volume at 15 $\mathrm{s}(7 \%, p=0.048, d=0.37)$ (Figure 1f). Cardiac output was different between the conditions $\left(\mathrm{F}_{(1,96)}=\right.$ $38.81, p<0.001)$, with no time $\left(\mathrm{F}_{(7,96)}=0.14, p=0.999\right)$ or interaction effect $\left(\mathrm{F}_{(7,96)}=0.29, p=0.955\right)$. NZBC increased cardiac output at $15(8 \%, p=0.048, d=0.37), 45(9 \%, p=0.056, d=0.60), 60(10 \%, p=$ $0.033, d=0.60), 75(10 \%, p=0.029, d=0.45), 90(12 \%, p=0.016, d=0.58), 105(10 \%, p=0.034, d=0.55)$ and $120 \mathrm{~s}(11 \%, p=0.013, d=0.54)$ (Figure 1g). Total peripheral resistance was different between the conditions $\left(\mathrm{F}_{(1,96)}=42.60, p=0.001\right)$, with no time $\left(\mathrm{F}_{(7,96)}=1.05, p=0.404\right)$ or interaction effect $\left(\mathrm{F}_{(7,96)}=\right.$ $0.25, p=0.972)$. NZBC decreased total peripheral resistance at $15(17 \%, p=0.012, d=0.41), 30(16 \%, p=$ $0.085, d=0.35), 45(25 \%, p=0.040, d=0.55), 60(25 \%, p=0.031, d=0.50), 90(21 \%, p=0.019, d=0.38)$, $105(29 \%, p=0.042, d=0.65)$ and $120 \mathrm{~s}(19 \%, p=0.024, d=0.54)$ (Figure 1h). 


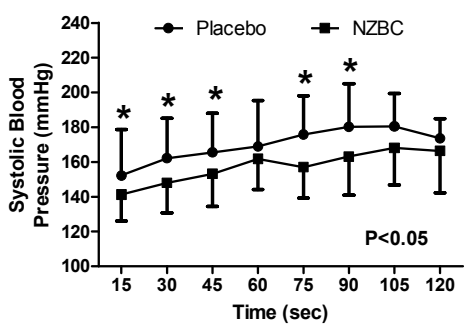

(a)

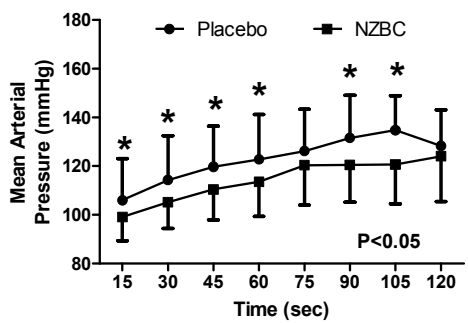

(c)

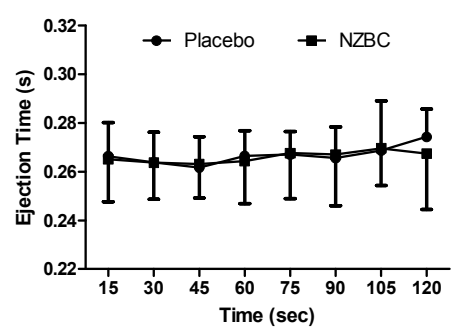

(e)

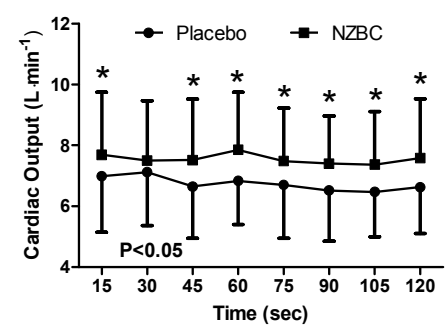

(g)

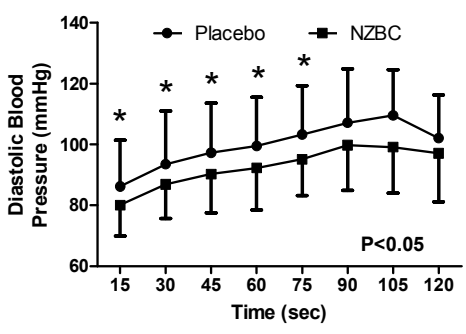

(b)

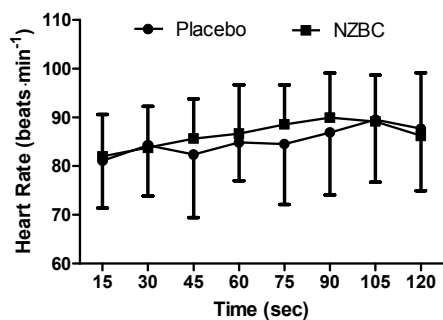

(d)

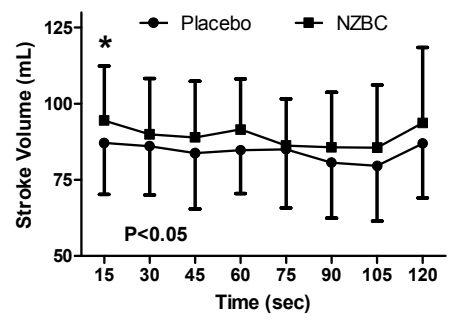

(f)

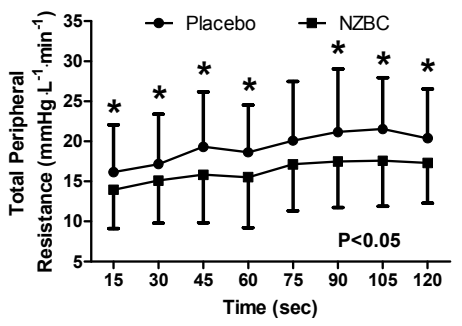

(h)

Figure 1. (a) Systolic Blood Pressure; (b) Diastolic Blood Pressure; (c) Mean Arterial Pressure; (d) Heart Rate; (e) Ejection Time; (f) Stroke Volume; (g) Cardiac Output; (h) Total Peripheral Resistance during a 120 -s 30\%iMVC of the quadriceps muscle for placebo and after 7-days intake of NZBC (New Zealand blackcurrant) extract capsules. Data are mean \pm SD. * difference between placebo and NZBC extract $(p<0.05)$.

\subsection{Electromyography}

During the sustained isometric contraction there was no condition $\left(\mathrm{F}_{(1,96)}=0.59, p=0.444\right)$, time $\left(\mathrm{F}_{(7,96)}=0.39, p=0.905\right)$ or interaction effect $\left(\mathrm{F}_{(7,96)}=0.12, p=0.996\right)$ on normalised EMG of muscle activation for the rectus femoris (Figure 2a). The normalised EMG for the vastus medialis showed a condition effect $\left.\left(\mathrm{F}_{(1,96)}=22.04\right), p<0.001\right)$, with no time $\left(\mathrm{F}_{(7,96)}=0.43, p=0.881\right)$ or interaction effect $\left(\mathrm{F}_{(7,96)}=0.34, p=0.935\right)$, with NZBC decreasing normalised RMS at $45(16 \%, p=0.050, d=0.68), 60$ $(12 \%, p=0.034, d=0.75)$ and $75 \mathrm{~s}(11 \%, p=0.015, d=0.75)$ (Figure $2 \mathrm{~b})$. For the biceps femoris, there was no condition $\left(\mathrm{F}_{(1,96)}=0.72, p=0.399\right)$, time $\left(\mathrm{F}_{(7,96)}=0.08, p=0.999\right)$ or interaction effect $\left(\mathrm{F}_{(7,96)}=0.04\right.$, $p=0.999)$. 


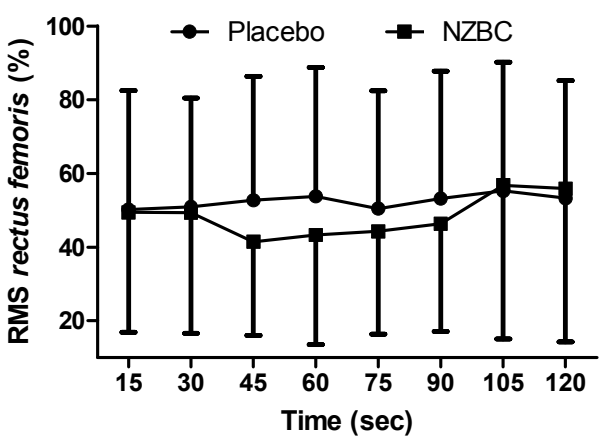

(a)

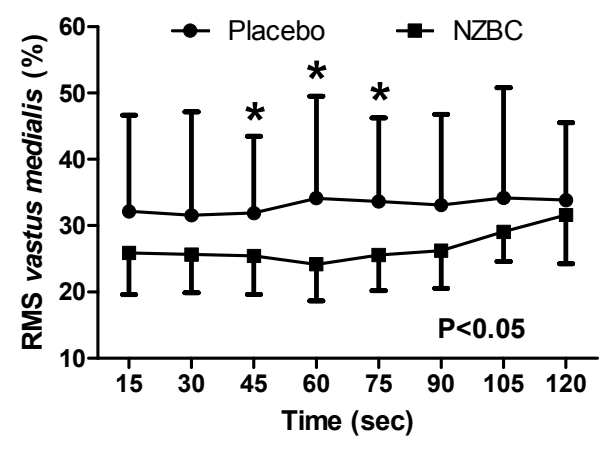

(b)

Figure 2. Normalised root mean square (RMS) of the rectus femoris muscle (a) and the vastus medialis muscle (b) during a 120 s 30\%iMVC for placebo and after 7-days intake of NZBC (New Zealand blackcurrant) extract capsules. Data are mean \pm SD. * difference between placebo and NZBC extract.

There was no difference in the slope of the MDF during the sustained contraction for the rectus femoris (NZBC: $-0.030 \pm 0.050$, PL: $-0.036 \pm 0.073, p=0.788$ ), vastus medialis (NZBC: $0.010 \pm 0.023$, PL: $0.008 \pm 0.053, p=0.879$ ) or biceps femoris (NZBC: $0.012 \pm 0.054$, PL: $0.011 \pm 0.049, p=0.955$ ).

\subsection{Near Infrared Spectroscopy}

At rest, there was a strong trend for $\mathrm{SmO}_{2} \%$ to be lower following NZBC (NZBC: $64 \pm 12$, PL: $70 \pm 11 \%, p=0.067$ ) with no difference in THb concentration (NZBC: $12.4 \pm 0.4, \mathrm{PL}: 12.2 \pm 0.3 \mathrm{~g} \cdot \mathrm{dL}^{-1}$, $p=0.145)$.

During the sustained isometric contraction, $\mathrm{SmO}_{2} \%$ was different between the conditions $\left(\mathrm{F}_{(1,96)}\right.$ $=30.12, p<0.001)$ with no time $\left(\mathrm{F}_{(7,96)}=0.29, p=0.958\right)$ or interaction effect $\left(\mathrm{F}_{(7,96)}=0.10, p=0.997\right)$ (Figure 3a). THb was different between the conditions $\left(\mathrm{F}_{(1,96)}=15.55, p<0.001\right)$ with no time $\left(\mathrm{F}_{(7,96)}\right.$, $p=1.000)$ or interaction effect $\left(\mathrm{F}_{(7,96)}=0.01, p=1.000\right)$ (Figure $\left.3 \mathrm{~b}\right)$. There were no time points different for either measure.

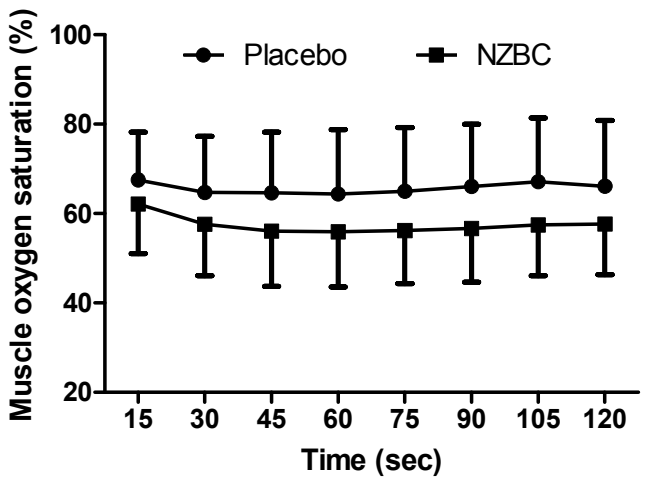

(a)

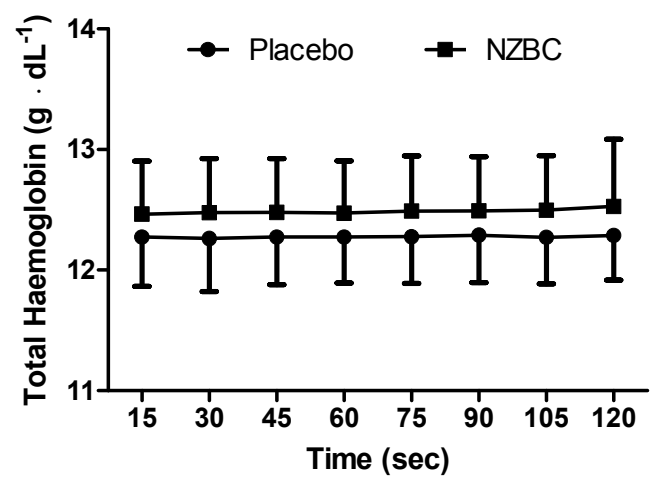

(b)

Figure 3. (a) Muscle oxygen saturation; (b) total haemoglobin concentration during a 120-s 30\%iMVC of the quadriceps muscle for placebo and after 7-days intake of NZBC (New Zealand blackcurrant) extract capsules. Data are mean \pm SD. * difference between placebo and NZBC extract.

\subsection{Femoral Artery Diameter}

There was no difference in femoral artery diameter at rest (NZBC: $0.75 \pm 0.07$, PL: $0.75 \pm 0.09 \mathrm{~cm}$, $p=0.902$ ) or $30 \mathrm{~s}$ following the sustained isometric contraction (NZBC: $0.75 \pm 0.12, \mathrm{PL}: 0.76 \pm 0.12 \mathrm{~cm}$, $p=0.687)$ for either experimental condition. 
During the sustained isometric contraction, there was a difference between the conditions $\left(\mathrm{F}_{(1,48)}\right.$ $=35.56, p<0.001)$, with no difference observed across time $\left(\mathrm{F}_{(3,48)}=0.03, p=0.993\right)$ or an interaction effect $\left(\mathrm{F}_{(3,48)}=0.23, p=0.874\right)$. Post hoc testing identified femoral artery diameter to be greater with NZBC (Figure 4) at $30(p=0.009, d=0.52), 60(p=0.003, d=0.80), 90(p=0.021, d=0.82)$ and $120 \mathrm{~s}$ $(p=0.022, d=0.58$ ) with increases of $6.9 \%$ (12 of 13 participants increased), 8.2\% (12 of 13 participants increased), $7.7 \%$ (11 of 13 participants increased) and 6.0\% (11 of 13 participants increased).

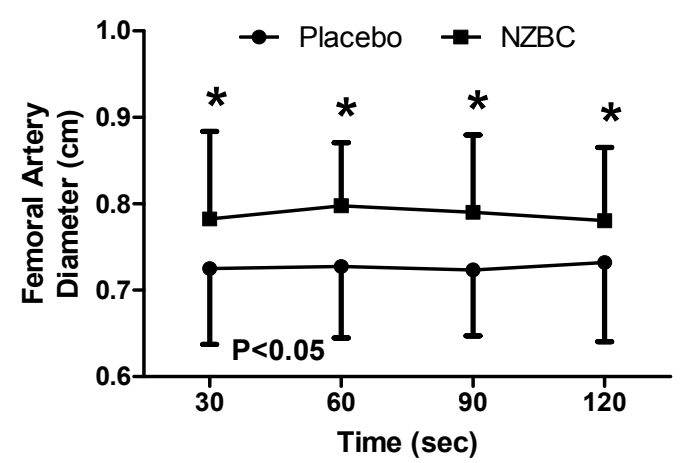

Figure 4. Femoral artery diameter during a 120-s 30\%iMVC of the quadriceps muscle for placebo and after 7-days intake of NZBC (New Zealand blackcurrant) extract capsules. Data are mean \pm SD. * difference between placebo and NZBC extract.

\section{Discussion}

The principal finding from the present study was that femoral artery diameter was increased with intake of NZBC extract during a submaximal (i.e., $30 \%$ iMVC) 120 -s sustained isometric contraction of the quadriceps muscles. The enlarged diameter of the femoral artery was accompanied by alterations in cardiovascular responses with a decrease in systolic and diastolic blood pressure, mean arterial blood pressure and total peripheral resistance with a concomitant increase in cardiac output and stroke volume. The normalised RMS for the vastus medialis and muscle oxygen saturation was also decreased while total haemoglobin concentration in the muscle was increased by the NZBC extract.

Regardless of the experimental condition within the present study (i.e., NZBC extract or placebo), the physiological responses during the sustained isometric contraction are similar to those of McNeil et al. [10]. For example, heart rate was unchanged while mean arterial blood pressure increased over time during an isometric contraction at $30 \%$ of MVC [10]. The cardiovascular function responses in the study by McNeil et al. [10] also occurred without an alteration in artery diameter (i.e., no observed time effect), or a change in normalised RMS during the contraction. An interesting observation from the present study is that NZBC increased femoral artery in comparison to a placebo at every time point during the contraction, however before and after the contraction, the diameter was not different.

The effect of the anthocyanins from the NZBC on vascular function and arterial diameter during the isometric contraction are thought to occur from them modulating an increase in concentration of nitric oxide [24,25]. However, as anthocyanins are reported to have low bioavailability [26], the bioactivity is likely mediated by the metabolites, that exist within the circulation at much higher concentrations $[27,28]$. An intake of anthocyanins with a similar dose to the present study increased flow-mediated dilation (FMD) $1 \mathrm{~h}$ following intake [8]. This occurred alongside a peak in the anthocyanin metabolites, ferulic acid, vanillic acid, isoferulic acid, 2-hydroxybenzoic acid and caffeic acid and a reduction in neutrophil NADPH oxidase. What is more, Edwards et al. [29] reported that the anthocyanin cyanidin-3-glucoside could increase eNOS expression, whereas the metabolites protocatechuic acid and vanillic acid did not. However, these metabolites elicited a reduction in superoxide production, which could decrease scavenging of nitric oxide. Therefore, while the anthocyanin can increase eNOS expression, metabolism of the anthocyanin into its metabolites loses this effect. However, the metabolites can maintain vascular homeostasis by increasing nitric oxide 
bioactivity through mechanisms involving NADPH inhibition or inducing cytoprotective enzyme haem oxygenase-1 (HO-1), an enzyme that catalyzes the degradation [29]. Similarly, Keane et al. [30] observed in pre-hypertensive males following $60 \mathrm{~mL}$ of Montmorency cherry ( $62 \mathrm{mg}$ anthocyanin) a peak reduction in systolic blood pressure of $7 \pm 2 \mathrm{mmHg} 2 \mathrm{~h}$ following intake, which occurred at the same time point as peak increases in the metabolites protocatechuic acid and vanillic acid within the plasma. Interestingly within this in vivo study, Keane et al. [30] observed no effect on plasma nitrate and nitrite (a proxy measure of nitric oxide production), further suggesting the metabolites are responsible for the vascular response. Indeed, this was also shown by Keane et al. [30], whereby, human vascular smooth muscles migrated further in vitro in response to a combination of the metabolites protocatechuic and vanillic acid, rather than when incubated in isolation. However, it should be noted that Czank et al. [27] observed 24 metabolites from the anthocyanin cyanidin-3-glucoside in human serum, which may suggest that many metabolites have to be examined for cardiovascular bioactivity rather than a few which have currently been studied.

It is considered unlikely within the present study that the intramuscular pressure from the isometric contraction was large enough to reduce blood flow into the muscle. Isometric contractions above $30 \%$ of MVC have been observed to reduce artery diameter [10], however no time effect for the artery diameter indicates the diameter at this contraction force and duration is consistent. Shoemaker et al. [31] reported that the day-to-day variation of an artery diameter during exercise ranged from $2.9 \pm 0.4 \%$ to $3.96 \pm 0.5 \%$. The increases of femoral artery diameter in the present study were $6.0-8.2 \%$ and above what would be expected within daily variation and therefore attributed to the intake of NZBC extract. The effect of intake of NZBC extract upon femoral artery diameter may also explain how the cardiovascular function was altered. It is postulated that the effect of intake of NZBC extract on vasodilation was not exclusive for the femoral artery; therefore, this would explain the lower total peripheral resistance, systolic and diastolic and mean arterial blood pressure. It is also noteworthy that some participants responded, while others did not. It is therefore possible that, similar to the findings of George et al. [32], NZBC anthocyanins influence vascular responses differently based upon genotype. George et al. [32] observed that vasodilation in the forearm following acute consumption of a high flavonoid fruit and vegetable puree drink was different for expressions of the eNOS gene Glu298Asp, whereby there was higher endothelium-dependent vasodilation in response to acetylcholine $180 \mathrm{~min}$ after intake in GG individuals compared to GT. Therefore, different expressions of this gene may explain the variation in responses in the present study. What is more, George et al. [32] measured vasodilation by laser Doppler imaging with iontophoresis on the forearm, therefore measurements made in a peripheral vessel are not representative of generalised endothelial function. Lastly, George et al. [32] measured acute responses and it is unknown if repeated supplementation over 7-days, as in the present study, would modulate these responses and is, therefore worth future study.

The present study provides novel observations on the effects of blackcurrant anthocyanins on NIRS parameters during submaximal isometric exercise. $\mathrm{SmO}_{2} \%$ by NIRS reflects the dynamic between $\mathrm{O}_{2}$ supply and $\mathrm{O}_{2}$ consumption [33]. Therefore, presuming a greater oxygen supply from increased femoral artery diameter and cardiac output in the present study, a consistently lower $\mathrm{SmO}_{2}(\%)$ following intake of NZBC extract could indicate greater extraction and utilisation of oxygen. This would then potentially explain the reduced RMS during the sustained contraction as oxygen utilisation is greater and results in reduced fatigue [34]. Another indirect measure of an increase in blood flow by NZBC was an increase in THb from the NIRS. This measure is made from a combination of haemoglobin and myoglobin. Assuming that blood haemoglobin concentration and relative contribution of myoglobin remains constant between the 7-day visits, an increase in absolute $\mathrm{THb}$ in the present study would indicate an increased amount of blood in the muscle. Although at rest, Bailey et al. [35] observed an increased $\mathrm{THb}$ following intake of beetroot with an elevated oxygenated haemoglobin response in the first $120 \mathrm{~s}$ and a reduced amplitude of the deoxygenated response by $13 \%$ during $360 \mathrm{~s}$ of moderate intensity cycling ( $80 \%$ of the gas exchange threshold). Unfortunately, the NIRS device used within the present study does not report deoxygenated values (combination of 
haemoglobin and myoglobin), therefore this comparison is not possible. However, within the study by Bailey et al. [35], the pulmonary oxygen uptake was reduced by $19 \%$, indicating that less $\mathrm{O}_{2}$ extraction was required as a consequence of reduced aerobic energy turnover or muscle energy utilisation. The association between decreased saturation, potentially indicating greater extraction, and increased $\mathrm{THb}$ with intake of NZBC extract may suggest more complex mechanisms. For example an increased extraction could be postulated to be a result of increased $\mathrm{VO}_{2}$. From the Fick equation [36], an increase in $\mathrm{O}_{2}$ delivery (i.e., from an increase in cardiac output) would be expected to enable an increased uptake of $\mathrm{O}_{2}$. However, Willems et al. [2] and Cook et al. [4] did not observe any alteration in oxygen uptake during exercise following NZBC, therefore this warrants further investigation. In addition, the present study did not measure the pulmonary oxygen uptake response to the isometric contraction; therefore, this mechanism is speculative. In addition, the NIRS technique is not without limitations. Firstly, skin and adipose tissue thickness affect sensitivity due to contamination of the signal [37]. Consequently, individual differences could not be controlled for in the present study. Another issue is that the small volume of tissue measured does not represent the whole muscle. For example, activation, metabolism and most importantly perfusion are heterogeneously distributed within and between exercising muscles [38]. This may explain why the normalised EMG was not different for the rectus femoris, but it was different for the vastus medialis.

It is postulated that the increased femoral artery diameter and increase in total haemoglobin by NIRS represents an increase in blood flow. During a sustained isometric contraction, the metabolic condition within the muscle is a function of local blood flow [39]. An interesting observation in the present study was that for the vastus medialis, the intake of NZBC extract decreased amplitude as measured by normalised RMS within the EMG. The RMS provides an indicator of motor unit activity; therefore a reduction would indicate less recruitment of progressively larger, fatigued motor units compensating for the fatigue of currently active motor units [40]. A change in MDF values is considered a useful physiological indicator of muscle fatigue [41], therefore no change in the slopes from the linear regression analysis suggests that intake of NZBC extract had no effect on fatigue in the $120 \mathrm{~s} 30 \%$ iMVC. Furthermore, the slopes were very shallow (i.e., for the vastus medialis $~ 0.010$ ), indicating that the sustained isometric contraction at this intensity and duration has a low fatiguing effect. A change to the slope to become steeper would be expected to occur from a decrease in membrane conduction velocity due to metabolic changes and ion shifts within the muscle [42]. However, this would only be expected for contractions in which blood flow was occluded or low-intensity isometric contractions to exhaustion.

\section{Limitations of the Study}

Firstly, the present study took measures during a submaximal isometric contraction, consequently, we cannot be certain that the observations would occur during rhythmical exercise whereby the muscles contraction-relaxation phases are shorter and of different intensity. Secondly, the bioavailability of anthocyanins is low, however metabolites have been observed within the plasma $48 \mathrm{~h}$ following intake [27]. Therefore, bioaccumulation of metabolites may have occurred and caused the effects in the present study. However, as the last intake was taken 2-h before the measurements, it cannot be excluded that an acute effect from that intake caused the responses in the present study. While dietary intake for the $48 \mathrm{~h}$ before the experimental visits was replicated using food diaries, there was no restriction on fruit and vegetable intake. As polyphenol metabolites are known to act synergistically, habitual fruit and vegetable intake may have contributed to the changes observed. In addition, implementation of a wash-out diet (i.e., low phenolic diet for $48 \mathrm{~h}$ before each experimental visit) would indicate that the NZBC intake was the likely definitive factor causing the increase in femoral artery diameter, however such approach lowers ecological validity for those in an exercise performance setting. Future studies may also wish to measure antioxidant status of participants and quantify the polyphenol and anthocyanin intake of participants. Thirdly, we do not know the ultrasonographic lower limb atherosclerosis score (i.e., ULLA score) [43], but the ULLA score is likely zero as our 
participants were young adult, non-smoking and physically active men. It would be of interest to examine the effectiveness of New Zealand blackcurrant intake on vasodilation in peripheral arterial disease patients.

\section{Conclusions}

Seven days intake of $600 \mathrm{mg} \cdot$ day $^{-1}$ of New Zealand blackcurrant extract containing $210 \mathrm{mg} \cdot$ day $^{-1}$ anthocyanins, with the final intake 2 to $3 \mathrm{~h}$ before testing, increased vasodilation during sustained submaximal isometric exercise in young adult healthy men. This occurs alongside alterations in whole body cardiovascular responses, a decrease in muscle oxygen saturation and amplitude of electromyography signal, and an increase in total haemoglobin. Taken together, an increase in vasodilation and cardiac output would indicate an increase in peripheral blood flow, thereby providing support for a potential mechanism of improved exercise performance as observed in previous studies.

Acknowledgments: Supply of placebo and supplement (CurraNZ $\left.{ }^{\mathrm{TM}}\right)$ for this study was obtained from Health Currancy Ltd. (United Kingdom). Funding for open access was provided by the University of Chichester.

Author Contributions: M.D.C., S.D.M., M.L.G. and M.E.T.W. designed the experiments; M.D.C. performed the experiments and analysed the data; M.D.C. and M.E.T.W. wrote the paper; S.D.M. and M.L.G. commented on drafts of the paper.

Conflicts of Interest: The authors declare no conflict of interest. Health Currancy Ltd had no role in the design of the study; in the collection, analyses, or interpretation of data; in the writing of the manuscript, and in the decision to publish the results.

\section{References}

1. Kähkönen, M.P.; Heinämäki, J.; Ollilainen, V.; Heinonen, M. Berry anthocyanins: isolation, identification and antioxidant activities. J. Sci. Food Agric. 2003, 83, 1403-1411. [CrossRef]

2. Willems, M.E.T.; Myers, S.D.; Gault, M.L.; Cook, M.D. Beneficial Physiological Effects with Blackcurrant Intake in Endurance Athletes. Int. J. Sport Nutr. Exerc. Metab. 2015, 25, 367-374. [CrossRef] [PubMed]

3. Cook, M.D.; Myers, S.D.; Gault, M.L.; Edwards, V.C.; Willems, M.E.T. Cardiovascular function during supine rest in endurance trained males with New Zealand blackcurrant: A dose-response study. Eur. J. Appl. Physiol. 2017, 117, 247-254. [CrossRef] [PubMed]

4. Cook, M.D.; Myers, S.D.; Blacker, S.D.; Willems, M.E.T. New Zealand blackcurrant extract improves cycling performance and fat oxidation in cyclists. Eur. J. Appl. Physiol. 2015, 115, 2357-2365. [CrossRef] [PubMed]

5. Perkins, I.C.; Vine, S.A.; Blacker, S.D.; Willems, M.E.T. New Zealand Blackcurrant Extract Improves High-Intensity Intermittent Running. Int. J. Sport Nutr. Exerc. Metab. 2015, 25, 487-493. [CrossRef] [PubMed]

6. Matsumoto, H.; Takenami, E.; Iwasaki-Kurashige, K.; Osada, T.; Katsumura, T.; Hamaoka, T. Effects of blackcurrant anthocyanin intake on peripheral muscle circulation during typing work in humans. Eur. J. Appl. Physiol. 2005, 94, 36-45. [CrossRef] [PubMed]

7. Ziberna, L.; Lunder, M.; Tramer, F.; Drevenšek, G.; Passamonti, S. The endothelial plasma membrane transporter bilitranslocase mediates rat aortic vasodilation induced by anthocyanins. Nutr. Metab. Cardiovasc. Dis. 2013, 23, 68-74. [CrossRef] [PubMed]

8. Rodriguez-Mateos, A.; Feliciano, R.P.; Boeres, A.; Weber, T.; Dos Santos, C.N.; Ventura, M.R.; Heiss, C. Cranberry (poly)phenol metabolites correlate with improvements in vascular function: A double-blind, randomized, controlled, dose-response, crossover study. Mol. Nutr. Food Res. 2016, 60, 2130-2140. [CrossRef] [PubMed]

9. Rodriguez-Mateos, A.; Rendeiro, C.; Bergillos-Meca, T.; Tabatabaee, S.; George, T.W.; Heiss, C.; Spencer, J.P. Intake and time dependence of blueberry flavonoid-induced improvements in vascular function: A randomized, controlled, double-blind, crossover intervention study with mechanistic insights into biological activity. Am. J. Clin. Nutr. 2013, 98, 1179-1191. [CrossRef] [PubMed]

10. McNeil, C.J.; Allen, M.D.; Olympico, E.; Shoemaker, J.K.; Rice, C.L. Blood flow and muscle oxygenation during low, moderate, and maximal sustained isometric contractions. Am. J. Physiol. Regul. Integr. Comp. Physiol. 2015, 309, R475-R481. [CrossRef] [PubMed] 
11. Sadamoto, T.; Bonde-Petersen, F.; Suzuki, Y. Skeletal muscle tension, flow, pressure, and EMG during sustained isometric contractions in humans. Eur. J. Appl. Physiol. Occup. Physiol. 1983, 51, 395-408. [CrossRef] [PubMed]

12. Sjøgaard, G.; Savard, G.; Juel, C. Muscle blood flow during isometric activity and its relation to muscle fatigue. Eur. J. Appl. Physiol. Occup. Physiol. 1988, 57, 327-335. [CrossRef] [PubMed]

13. Garland, S.J. Role of small diameter afferents in reflex inhibition during human muscle fatigue. J. Physiol. 1991, 435, 547-558. [CrossRef] [PubMed]

14. Bigland-Ritchie, B.R.; Dawson, N.J.; Johansson, R.S.; Lippold, O.C. Reflex origin for the slowing of motoneurone firing rates in fatigue of human voluntary contractions. J. Physiol. 1986, 379, 451-459. [CrossRef] [PubMed]

15. Mense, S.; Stahnke, M. Responses in muscle afferent fibres of slow conduction velocity to contractions and ischaemia in the cat. J. Physiol. 1983, 342, 383-397. [CrossRef] [PubMed]

16. Rotto, D.M.; Kaufman, M.P. Effect of metabolic products of muscular contraction on discharge of group III and IV afferents. J. Appl. Physiol. 1988, 64, 2306-2313. [PubMed]

17. Shoemaker, J.K.; MacDonald, M.J.; Hughson, R.L. Time course of brachial artery diameter responses to rhythmic handgrip exercise in humans. Cardiovasc. Res. 1997, 35, 125-131. [CrossRef]

18. Connolly, D.A.; McHugh, M.P.; Padilla-Zakour, O.I.; Carlson, L.; Sayers, S.P. Efficacy of a tart cherry juice blend in preventing the symptoms of muscle damage. Br. J. Sports Med. 2006, 40, 679-683. [CrossRef] [PubMed]

19. Howatson, G.; McHugh, M.P.; Hill, J.A.; Brouner, J.; Jewell, A.P.; van Someren, K.A.; Shave, R.E.; Howatson, S.A. Influence of tart cherry juice on indices of recovery following marathon running. Scand. J. Med. Sci. Sports 2010, 20, 843-852. [CrossRef] [PubMed]

20. Bowtell, J.L.; Sumners, D.P.; Dyer, A.; Fox, P.; Mileva, K.N. Montmorency cherry juice reduces muscle damage caused by intensive strength exercise. Med. Sci. Sports Exerc. 2011, 43, 1544-1551. [CrossRef] [PubMed]

21. Gandevia, S.C. Spinal and supraspinal factors in human muscle fatigue. Physiol. Rev. 2001, 81, 1725-1789. [PubMed]

22. Peñáz, J. Photoelectric measurements of blood pressure, volume and flow in the finger. In Proceedings of the Digest of the 10th International Conference on Medical and Biological Engineering, Dresden, Germany, 13-17 August 1973; p. 104.

23. Cohen, J. Statistical Power Analysis for the Behavioral Sciences, 2nd ed.; Erlbaum Associates: Hillsdale, MI, USA, 1998.

24. Xu, J.W.; Ikeda, K.; Yamori, Y. Cyanidin-3-glucoside regulates phosphorylation of endothelial nitric oxide synthase. FEBS Lett. 2004, 574, 176-180. [CrossRef] [PubMed]

25. Xu, J.W.; Ikeda, K.; Yamori, Y. Upregulation of endothelial nitric oxide synthase by cyanidin-3-glucoside, a typical anthocyanin pigment. Hypertension 2004, 44, 217-222. [CrossRef] [PubMed]

26. Kay, C.D. Aspects of anthocyanin absorption, metabolism and pharmacokinetics in humans. Nutr. Res. Rev. 2006, 19, 137-146. [CrossRef] [PubMed]

27. Czank, C.; Cassidy, A.; Zhang, Q.; Morrison, D.J.; Preston, T.; Kroon, P.A.; Botting, N.P.; Kay, C.D. Human metabolism and elimination of the anthocyanin, cyanidin-3-glucoside: A (13)C-tracer study. Am. J. Clin. Nutr. 2013, 97, 995-1003. [CrossRef] [PubMed]

28. de Ferrars, R.M.; Cassidy, A.; Curtis, P.; Kay, C.D. Phenolic metabolites of anthocyanins following a dietary intervention study in post-menopausal women. Mol. Nutr. Food Res. 2014, 58, 490-502. [CrossRef] [PubMed]

29. Edwards, M.; Czank, C.; Woodward, G.M.; Cassidy, A.; Kay, C.D. Phenolic metabolites of anthocyanins modulate mechanisms of endothelial function. J. Agric. Food Chem. 2015, 63, 2423-2431. [CrossRef] [PubMed]

30. Keane, K.M.; George, T.W.; Constantinou, C.L.; Brown, M.A.; Clifford, T.; Howatson, G. Effects of Montmorency tart cherry (Prunus Cerasus L.) consumption on vascular function in men with early hypertension. Am. J. Clin. Nutr. 2016, 103, 1531-1539. [CrossRef] [PubMed]

31. Shoemaker, J.K.; Pozeg, Z.I.; Hughson, R.L. Forearm blood flow by Doppler ultrasound during test and exercise: Tests of day-to-day repeatability. Med. Sci. Sports Exerc. 1996, 28, 1144-1149. [CrossRef] [PubMed]

32. George, T.W.; Waroonphan, S.; Niwat, C.; Gordon, M.H.; Lovegrove, J.A. The Glu298Asp single nucleotide polymorphism in the endothelial nitric oxide synthase gene differentially affects the vascular response to acute consumption of fruit and vegetable puree based drinks. Mol. Nutr. Food Res. 2012, 56, 1014-1024. [CrossRef] [PubMed] 
33. Ferrari, M.; Muthalib, M.; Quaresima, V. The use of near-infrared spectroscopy in understanding skeletal muscle physiology: Recent developments. Philos. Trans. A Math. Phys. Eng. Sci. 2011, 369, 4577-4590. [CrossRef] [PubMed]

34. Rozand, V.; Cattagni, T.; Theurel, J.; Martin, A.; Lepers, R. Neuromuscular fatigue following isometric contractions with similar torque time integral. Int. J. Sports Med. 2015, 36, 35-40. [CrossRef] [PubMed]

35. Bailey, S.J.; Winyard, P.; Vanhatalo, A.; Blackwell, J.R.; Dimenna, F.J.; Wilkerson, D.P.; Dimenna, F.J.; Wilkerson, D.P.; Tarr, J.; Benjamin, N.; et al. Dietary nitrate supplementation reduces the $\mathrm{O}_{2}$ cost of low-intensity exercise and enhances tolerance to high-intensity exercise in humans. J. Appl. Physiol. 2009, 107, 1144-1155. [CrossRef] [PubMed]

36. Fick, A. Uber die messung des Blutquantums in de Hertzvent rikeln. In Landmarks of Science E Medicine from the Library of Andras Gedeon; Christie's: London, UK, 1870.

37. Grassi, B.; Quaresima, V. Near-infrared spectroscopy and skeletal muscle oxidative function in vivo in health and disease: A review from an exercise physiology perspective. J. Biomed. Opt. 2016, 21, 091313. [CrossRef] [PubMed]

38. Koga, S.; Rossiter, H.B.; Heinonen, I.; Musch, T.I.; Poole, D.C. Dynamic heterogeneity of exercising muscle blood flow and $\mathrm{O}_{2}$ utilization. Med. Sci. Sports Exerc. 2014, 46, 860-876. [CrossRef] [PubMed]

39. Zwarts, M.J.; Arendt-Nielsen, L. The influence of force and circulation on average muscle fibre conduction velocity during local muscle fatigue. Eur. J. Appl. Physiol. Occup. Physiol. 1988, 58, 278-283. [CrossRef] [PubMed]

40. Löscher, W.N.; Cresswell, A.G.; Thorstensson, A. Electromyographic responses of the human triceps surae and force tremor during sustained submaximal isometric plantar flexion. Acta Physiol. Scand. 1994, 152, 73-82. [CrossRef] [PubMed]

41. Crenshaw, A.G.; Karlsson, S.; Gerdle, B.; Fridén, J. Differential responses in intramuscular pressure and EMG fatigue indicators during low- vs. high-level isometric contractions to fatigue. Acta Physiol. Scand. 1997, 160, 353-361. [CrossRef] [PubMed]

42. Béliveau, L.; Van Hoecke, J.; Garapon-Bar, C.; Gaillard, E.; Herry, J.P.; Atlan, G.; Bouissou, P. Myoelectrical and metabolic changes in muscle fatigue. Int. J. Sports Med. 1992, 13 (Suppl 1.), S153-S155. [CrossRef] [PubMed]

43. Santoro, L.; Ferraro, P.M.; Flex, A.; Nesci, A.; De Matteis, G.; Di Giorgio, A.; Zaccone, V.; Gambaro, G.; Gasbarrini, A.; Santoliquido, A. New semiquantitative ultrasonographic score for peripheral arterial disease assessment and its association with cardiovascular risk factors. Hypertens. Res. 2016, 39, 868-873. [CrossRef] [PubMed]

(C) 2017 by the authors. Licensee MDPI, Basel, Switzerland. This article is an open access article distributed under the terms and conditions of the Creative Commons Attribution (CC BY) license (http://creativecommons.org/licenses/by/4.0/). 